\title{
Critical Examination of Reported Energy Intake in Published Dietary Studies of Japanese Subjects Using the Goldberg Cut-Off
}

\author{
Kentaro MURAKAMI \\ Department of Food and Nutritional Sciences, Graduate School of Nutritional and Environmental Sciences, \\ University of Shizuoka, Shizuoka 422-8526, Japan
}

(Received June 12, 2003)

\begin{abstract}
Summary Although it is now generally acknowledged in Western countries that mismeasurement (under- and overestimation) of dietary intake is a serious problem in studies on diet and health, the validity of dietary assessment methods in Japan has seldom been externally evaluated with objective measures. This study used the Goldberg cut-off to examine whether the energy intake in Japan could be regarded as a measure of habitual energy intake at the group level. Examined here were six published dietary studies in Japan providing 14 subgroups when divided by sex and dietary assessment method. Reported energy intake was expressed as a multiple of basal metabolic rate estimated using equations (EI/ BMR). EI/BMR was compared with the subgroup-specific cut-off values representing the lowest and highest values of EI/BMR that could reflect the habitual energy expenditure. Mean EI/BMR was $1.49(\mathrm{SD}=0.09)$, which was lower than an expected requirement of 1.55. When all 14 subgroups were combined, seven subgroups (50\%) had an EI/BMR less than the subgroup-specific lower cut-off value, and one $(7 \%)$ had the ratio greater than the upper value. The percentages of subgroups having the ratio less than the lower value and greater than the upper value ranged from 43 to $57 \%$ and from 0 to $14 \%$, respectively, when subgroups of women $(n=8)$, men $(n=6)$, diet record $(n=7)$, and questionnaire method $(n=7)$ were evaluated separately. These findings suggest that responsible investigators in Japan should critically examine dietary intake data in any study of diet and health.
\end{abstract}

Key Words energy intake, Goldberg cut-off, Japanese people

In studies where the relationships between diet and health are examined, accurate assessment of habitual dietary intakes is a pre-requisite. Responsible investigators have made great efforts to develop and validate a wide range of dietary assessment methods. Dietary assessment methods can be divided into three generic categories $(1,2)$ : recall of actual foods eaten; retrospective questionnaire or histories of the typical or habitual diet; and prospective diet records. The diet record has been often assumed to be a reference method simply because the quantitative nature of the data and its presumed superior precision $(2,3)$; consequently, this method has been widely used to validate other dietary assessment methods (4). However, it is not possible to conclude which method, if any, measures the true or valid dietary intake in the absence of external validation $(2,5)$. Good agreement between the test and reference methods may simply indicate similar errors in both methods $(3,6)$.

In Western countries, underestimation of dietary intake at the group level has been extensively observed when reported energy intake (EI) is externally evaluated against total energy expenditure measured with the doubly labeled water method (5) and presumed energy requirements (the Goldberg cut-off) for light

E-mail: p3131@mail.f.u-shizuoka-ken.ac.jp activity (2). Overestimation has also occurred in some individuals (7-9). Thus, it is now generally acknowledged in Western countries that mismeasurement (under- and overestimation) of dietary intake is a serious problem in studies of diet and health. The validity of methods for assessing dietary intakes of Japanese people, however, has been independently examined in only a limited number of studies $(10-20)$ and has been inconclusive. The Japanese diet, characterized by a large number of food items per meal, various cooking methods and seasonal variations (21) differs substantially from that in Western countries. The validity of dietary assessment methods in Japan, therefore, may be different from that in Western countries. In the present paper, Goldberg cut-off was used to examine whether the reported EI in published dietary studies of Japanese subjects could represent the habitual intake of those populations.

\section{MATERIALS AND METHODS}

Materials examined here were identified by using the following three inclusion criteria: 1) studies that assessed the relative validity of newly developed dietary assessment methods or the within- and between-individual variations of dietary intakes in Japan; 2) studies where the subjects were required to record their diet for $\geq 7 \mathrm{~d}$ and/or complete a detailed questionnaire that 
included $\geq 100$ questions on their usual diet; and 3) studies where the mean value of body weight of the subjects were available for men and women separately. The first criterion was set to include studies that seemed to perform an extremely careful collection of dietary data. The second made it possible to include highly selected and well-motivated subjects. The third was needed to calculate the basal metabolic rate (BMR) described later. Consequently, six studies $(12,22-26)$ were included in the present analyses. When studies involved repeated measurements of dietary intake using the questionnaire method, only first measurement was used here.

Reported EI was evaluated using the Goldberg cut-off $(27,28)$. In this technique, mean EI is expressed as a multiple of the mean BMR estimated from published equations (EI/BMR). This value is compared with the presumed mean energy expenditure (energy requirement) of the population, which is also expressed as a multiple of the BMR (expressed as physical activity level: PAL). The equation of Goldberg et al. $(27,28)$ calculates the lower and upper 95\% confidence limits of EI/BMR assuming a given PAL requirement, below or above which it is unlikely that the mean intake represents either habitual intake or low or high intakes obtained by chance, making allowance for errors in the techniques involved.

The EI/BMR was calculated for men and women separately in each study. The mean value of the following two BMRs was used as the BMR value for each group: the BMR calculated from reported weight using the Schofield equations (29); and the BMR calculated from reported weight using the equations reported in Japanese Recommended Dietary Allowance (30). This was because the BMR predicted with the Schofield equations was somewhat higher ( $84 \mathrm{kcal})$ and the BMR predicted with the equations reported in Japanese Recommended Dietary Allowance was somewhat lower $(-68 \mathrm{kcal})$ than the measured BMR, when the data of $2832 \mathrm{BMR}$ measurements of Japanese subjects were examined (31).

The Goldberg cut-offs (lower and upper cut-off values) for each group were calculated from the following equations:

Lower cut-off values $=\mathrm{PAL} \times \exp \left[\mathrm{SD}_{\min } \times(S / 100) / \sqrt{n}\right]$

Upper cut-off values $=\mathrm{PAL} \times \exp \left[\mathrm{SD}_{\max } \times(S / 100) / \sqrt{n}\right]$ where PAL is the assumed average PAL for the population under study, $\mathrm{SD}_{\min }$ (lower limit for $\mathrm{SD}$ score) is -2 for $95 \%$ confidence limit, $\mathrm{SD}_{\max }$ (upper limit for SD score) is +2 for $95 \%$ confidence limit, and $n$ is the number of subjects in the study. $S$ is the factor that takes account of the variation in EI, BMR, and energy requirements, and is given by

$$
S=\sqrt{\left[\mathrm{CV}^{2}{ }_{\mathrm{wEI}} / d+\mathrm{CV}^{2}{ }_{\mathrm{wB}}+\mathrm{CV}^{2}{ }_{\mathrm{tP}}\right]}
$$

where $\mathrm{CV}_{\mathrm{wEI}}$ is the within-subject variation in $\mathrm{EI}, d$ is the number of days of diet assessment, $\mathrm{CV}_{\mathrm{wB}}$ is the precision of estimated BMR compared with measured BMR, and $\mathrm{CV}_{\mathrm{tP}}$ is the between-subject variation in PAL. The CV values calculated using the data of Western countries were used ( $\mathrm{CV}_{\mathrm{wEI}} 23 \%, \mathrm{CV}_{\mathrm{wB}} 8.5 \%$, and $\mathrm{CV}_{\mathrm{tP}} 15 \%$ (28)) (see DISCUSSION). Where the assessment purports to mea- sure habitual intake for 1 mo or $1 \mathrm{y}, d=30$ and 365 were used, respectively. To the author's knowledge, only a small number of data on PAL of Japanese people have been available $(11,13,14,20,32)$; therefore the traditional PAL of 1.55 (the WHO value for 'light' activity or a sedentary lifestyle) (33) was used (see DISCUSSION).

The EI/BMR was calculated for each group made by dividing by sex and dietary assessment method used. The EI/BMR was compared with the calculated lower and upper cut-off values for each group to examine whether the EI could be regarded as a measure of habitual EI at the group level. Subgroups with an EI/BMR value less than the lower cut-off or greater than the upper cut-off were deemed underestimation or overestimation, respectively. Subgroups that had an EI/BMR value within the lower and upper cut-off values were regarded as acceptable estimation. All data analyses were carried out using the statistical package SPSS 11.0 for Windows (SPSS Japan Inc.).

\section{RESULTS}

Fourteen subgroups were obtained when the six studies examined were divided by sex and dietary assessment method. Table 1 presents the characteristics of the studies examined, including the number, sex, age, and occupation of subjects, the dietary assessment methods used, the mean height and weight, the reported EI, the calculated BMR, and the subgroup-specific Goldberg cut-off values. Mean $( \pm S D)$ EI/BMR was 1.49 ( \pm 0.09 ), which was lower than the PAL of 1.55 .

Table 2 shows the number and percentage of subgroups that were identified as underestimation, acceptable estimation or overestimation, using the Goldberg cut-off. When all subgroups were combined, seven (50\%) of fourteen subgroups had an EI/BMR ratio less than the subgroup-specific lower cut-off value and one ( $7 \%$ ) had the ratio greater than the upper cut-off value. This indicates that these reported intakes have only a $2.5 \%$ likelihood of reflecting habitual EI for a sedentary lifestyle because the Goldberg equation calculates the lower and upper 95\% confidence limits of EI/BMR assuming a given PAL requirement.

Differences of dietary assessment methods used seemed not to create large differences in the proportion of mismeasurement (Table 2), although the EI/BMR of the dietary record method subgroups $(n=7)$ was lower than that of the dietary assessment questionnaire method subgroups $(n=7)(1.46 \pm 0.07$ vs. $1.53 \pm 0.09)$. Differences of sex in the proportion of mismeasurement were also examined, and the same tendency of the proportion of mismeasurement was observed (Table 2). The mean $( \pm S D)$ EI/BMR was $1.50( \pm 0.10)$ for the female subgroups $(n=8)$ compared with $1.48( \pm 0.06)$ for the male subgroups $(n=6)$.

\section{DISCUSSION}

EI is the foundation of the diet because all other nutrients must be provided within the quantity of food needed to fulfill the energy requirement (5). Reported EI is therefore a surrogate measure of the total quantity of 
Table 1. Subjects' characteristics, dietary assessment methods used, reported energy intake (EI), basal metabolic rate (BMR), EI/BMR from published studies of Japanese subjects, and the Goldberg cut-off values.

\begin{tabular}{|c|c|c|c|c|c|c|c|c|c|c|}
\hline \multirow{2}{*}{$\begin{array}{c}\text { Ref. } \\
\text { no }\end{array}$} & \multicolumn{3}{|r|}{ Subjects } & \multirow{2}{*}{$\begin{array}{l}\text { Dietary } \\
\text { assessment } \\
\text { method }\end{array}$} & \multirow{2}{*}{$\begin{array}{l}\text { Mean } \\
\text { height } \\
(\mathrm{m})\end{array}$} & \multirow{2}{*}{$\begin{array}{l}\text { Mean } \\
\text { weight } \\
(\mathrm{kg})\end{array}$} & \multirow{2}{*}{$\begin{array}{l}\text { BMR } \\
\text { (kcal) }\end{array}$} & \multirow{2}{*}{$\begin{array}{c}\text { EI } \\
(\mathrm{kcal})\end{array}$} & \multirow{2}{*}{$\begin{array}{c}\text { EI/ } \\
\text { BMR }\end{array}$} & \multirow{2}{*}{$\begin{array}{l}\text { Goldberg cut- } \\
\text { off (lower and } \\
\text { upper values) }\end{array}$} \\
\hline & $\begin{array}{l}\text { Number } \\
\text { and sex }\end{array}$ & $\begin{array}{c}\text { Age } \\
(\text { mean } \pm S D)\end{array}$ & Occupation & & & & & & & \\
\hline \multirow[t]{2}{*}{22} & 42 women & $49.8 \pm 8.6$ & Family members of students & $4 \times 4-\mathrm{d} W \mathrm{R}$ & 1.544 & 53.9 & 1226 & 1646 & 1.34 & $1.47-1.64$ \\
\hline & 46 men & $52.5 \pm 4.5$ & Family members of students & $4 \times 4-\mathrm{d} W \mathrm{R}$ & 1.670 & 62.8 & 1472 & 2063 & 1.40 & $1.47-1.64$ \\
\hline \multirow[t]{2}{*}{12} & 44 women & $43.2 \pm 10.6$ & University workers & $\mathrm{DHQ}$ for $1 \mathrm{~m}$ & 1.590 & 52.8 & 1212 & 1968 & 1.62 & $1.47-1.64$ \\
\hline & 42 men & $41.9 \pm 8.3$ & University workers & $\mathrm{DHQ}$ for $1 \mathrm{~m}$ & 1.701 & 64.5 & 1532 & 2253 & 1.470 & $1.467-1.64$ \\
\hline 23 & 79 women & $48 \pm 8$ & Dietitians & $\mathrm{FFQ}$ for $1 \mathrm{~m}$ & 1.560 & 52.2 & 1205 & 1763 & 1.46 & $1.49-1.61$ \\
\hline 24 & 80 women & $48 \pm 8$ & Dietitians & $4 \times 7-d W R$ & 1.569 & 52.2 & 1205 & 1820 & 1.51 & $1.49-1.61$ \\
\hline \multirow[t]{4}{*}{25} & 176 women & $55.9 \pm 7.1$ & Housewife $(50.6 \%)$, employee & $4 \times 7-\mathrm{d} W R$ & 1.527 & 55.2 & 1212 & 1723 & 1.42 & $1.51-1.59$ \\
\hline & & & $\begin{array}{l}(30.7 \%) \text { agricultural worker } \\
(13.6 \%) \text {, self-employed }(5.1 \%) \text {, } \\
\text { professional }(5.1 \%) \text {, unem- } \\
\text { ployed }(5.1 \%) \text {, other }(5.1 \%)\end{array}$ & FFQ for $1 \mathrm{y}$ & & & & 1813 & 1.50 & $1.51-1.59$ \\
\hline & 174 men & $58.9 \pm 7.6$ & Employee (56.3\%), agricultur- & $4 \times 7-d W R$ & 1.649 & 64.6 & 1497 & 2220 & 1.48 & $1.51-1.59$ \\
\hline & & & $\begin{array}{l}\text { al worker }(18.4 \%) \text {, unem- } \\
\text { ployed }(17.2 \%) \text {, self-employed } \\
(10.9 \%) \text {, professional }(6.3 \%) \text {, } \\
\text { fishery worker }(0.6 \%) \text {, other } \\
(1.1 \%)\end{array}$ & FFQ for $1 \mathrm{y}$ & & & & 2132 & 1.42 & $1.51-1.59$ \\
\hline \multirow[t]{3}{*}{26} & 113 women & $53.3 \pm 5.3$ & Housewife $(47.8 \%)$, company & $2-4 \times 7-d W R$ & 1.511 & 54.6 & 1205 & 1820 & 1.51 & $1.50-1.60$ \\
\hline & & & $\begin{array}{l}\text { employee }(25.7 \%) \text {, agricultur- } \\
\text { al worker }(22.1 \%) \text {, self-em- } \\
\text { ployed }(10.6 \%), \text { professional } \\
(10.6 \%) \text {, forestry worker }(0.9 \%) \text {, } \\
\text { unemployed }(0.9 \%) \text {, other } \\
(5.3 \%)\end{array}$ & FFQ for $1 \mathrm{y}$ & & & & 2018 & 1.67 & $1.50-1.60$ \\
\hline & 102 men & $55.6 \pm 5.2$ & $\begin{array}{l}\text { Company employee }(55.9 \%) \text {, } \\
\text { agricultural worker }(30.4 \%) \text {, } \\
\text { self-employed }(13.7 \%) \text {, profes- } \\
\text { sional }(9.8 \%) \text { unemployed } \\
(5.9 \%) \text {, fishery worker }(2.9 \%) \text {, } \\
\text { other }(4.9 \%)\end{array}$ & $\begin{array}{c}2-4 \times 7-\mathrm{d} W R \\
\text { FFQ for } 1 \mathrm{y}\end{array}$ & 1.645 & 65.8 & 1514 & $\begin{array}{l}2347 \\
2352\end{array}$ & $\begin{array}{l}1.55 \\
1.55\end{array}$ & $\begin{array}{l}1.50-1.61 \\
1.50-1.61\end{array}$ \\
\hline
\end{tabular}

Abbreviations: BMR, basal metabolic rate; EI, energy intake; EI/BMR, energy intake : basal metabolic rate ratio; WR, weighed diet record; DHQ, diet history questionnaire; FFQ, food frequency questionnaire.

Table 2. The number and percentage of subgroups identified as underestimation, acceptable estimation, or overestimation using the Goldberg cut-off.

\begin{tabular}{lccc}
\hline & $\begin{array}{c}\text { Underestimation } \\
n(\%)\end{array}$ & $\begin{array}{c}\text { Acceptable estimation } \\
n(\%)\end{array}$ & $\begin{array}{c}\text { Overestimation } \\
n(\%)\end{array}$ \\
\hline All subgroups & $7(50.0)$ & $6(42.9)$ & $1(7.1)$ \\
Record methods & $4(57.1)$ & $3(42.9)$ & $0(0.0)$ \\
Questionnaire methods & $3(42.9)$ & $3(42.9)$ & $1(14.3)$ \\
Women & $4(50.0)$ & $3(37.5)$ & $1(12.5)$ \\
Men & $3(50.0)$ & $3(50.0)$ & $0(0.0)$ \\
\hline
\end{tabular}

food intake, and evaluating the validity of reported EI provides a valuable check on the general quality of the reported data in any study (5). In the present paper, it was critically examined whether the reported EI of 14 subgroups in six published dietary studies in Japan could represent the habitual intake of those populations using the Goldberg cut-off. It was found that only six (43\%) reported intakes out of 14 subgroups had a $95 \%$ likelihood of reflecting habitual EI, which is extremely undesirable. The percentages of acceptable estimation were similar when subgroups were made by sex (women: 38\% and men: 50\%) or the dietary assessment method used (both record and questionnaire methods: 43\%). However, while the food record assesses actual food consumption within several days, the questionnaire method is typically used for qualitative assessments of dietary patterns after normalizing nutrient intakes for EI (34); therefore, it should be noted that the underestimation of EI from questionnaire methods observed here does not necessarily indicate the lack of 
the ability and utility of these methods.

This study has several limitations. Firstly, only a small number of subgroups were examined in the present paper as a result of using only data obtained in studies where not only intensive dietary surveys took place but also information on subjects' weight was collected. Secondly, the BMRs used here were predicted using the published equations rather than measured. To minimize errors in predicted BMRs, however, the average value of the BMR calculated from the Schofield equation (29) and that from the equations reported in Japanese Recommended Dietary Allowance (30) was used (see MATERIALS AND METHODS). Moreover, errors in predicted BMRs were taken into account in the calculation of the Goldberg cut-off. Thirdly, the CV values used here were recommended values by Black (28), which were based on the data of Western countries. However, the CV values estimated using a limited number of data of Japanese people were comparable to these values from data of Western countries $\left(\mathrm{CV}_{\mathrm{wEI}}\right.$ $17.7 \%(22,24,35,36), \mathrm{CV}_{\mathrm{wB}} 8.6 \%$ (31), and $\mathrm{CV}_{\mathrm{tP}}$ $16.2 \%(11,13,14,20,32))$. Furthermore, using the CV values from data of Japanese people did not change the results of percentages of under-, acceptable, and overestimation of EI at all.

Finally, the PAL for a sedentary lifestyle (1.55) was used in the present study. This was because it may be difficult to set an appropriate PAL for each subgroup by using only available data such as subjects' occupation. This was also to avoid an overestimation of the prevalence of underestimation. Only a limited number of studies have examined the PAL of free-living Japanese subjects. Mean PAL of healthy Japanese men aged 22$28 \mathrm{y}(n=10)$ was 1.63 in a study where total energy expenditure was measured for 14 days using the doubly labeled water method (14). Rafamantanantsoa et al. (32) have also reported that mean PAL of 40 healthy Japanese men (30-69 y) was 1.85 using total energy expenditure by the doubly labeled water method. Additionally, doubly labeled water studies in Western countries have also indicated that the mean PAL of healthy, normally active free-living individuals aged 18-74 y in affluent societies is higher than the previously expected PAL of 1.55 with a range of 1.60 to 1.85 (37). Thus, it is highly probable that mean PAL of Japanese subjects is higher than the PAL used here; therefore, the possibility that the prevalence of EI underestimation is overestimated in the present paper may be quite small. Given the limitations mentioned above, the generalization of the results may be difficult; nevertheless, the results of this study should provide responsible investigators in Japan with an awareness that dietary intake data should be critically examined even in studies where intake data are carefully collected, while a large number of intake data in Japan have been reported as valid without examination.

The Goldberg cut-off applied in the present study was developed by Goldberg et al. (27) and used by Black et al. (2). Black et al. (2) calculated the EI/BMRs of 68 subgroups in Western countries and compared those with the subgroup-specific lower Goldberg cut-off value. The mean EI/BMR in the previous study was lower than that obtained in the present study (1.43 vs. 1.49$)$, and the percentage of subgroups that had an EI/BMR ratio less than the subgroup-specific lower cut-off value in the study by Black et al. (2) was higher than that in the present study (68\% vs. $50 \%$ ). These seemingly indicate that the possibility of EI underestimation by Japanese subjects is lower compared with that by Western people. However, it may be difficult to draw direct comparison between the study by Black et al. (2) and the present study. This is because the BMR used in the present study was the mean value of two calculated BMRs by published equations (see MATERIALS AND METHODS), while Black et al. (2) used the Schofield equation (29) to calculate the BMR. In addition, only a small number of subgroups were examined in the present study; therefore, further research should investigate the question whether Japanese people underestimate their EI less frequently than Western people do.

In the present study, only one out of 14 subgroups was identified as overestimation. Because a relatively low PAL of 1.55 was used, it may be highly possible that the prevalence of EI overestimation is overestimated. Moreover, in the previous study by Black et al. (2), evaluation of EI overestimation was not conducted because of the lack of information on PAL in free-living subjects. Thus, little information on overestimation of EI is available in the meantime. However, while underestimation of EI has been a major concern in dietary surveys, overestimation by some groups of individuals has also been observed (7-9); therefore, not only EI underestimation but also overestimation of EI should be taken into account in dietary surveys.

These findings provide no information regarding the patterns of bias from individuals in a surveyed population. A study carried out in the UK has demonstrated that mismeasurement is a continuous variable with a mean $-20 \%$ ranging from -50 to $+40 \%$ in randomly selected free-living adults (38). In addition, it has been observed that the degree of mismeasurement between two periods, and/or two methods, is constant within subjects. This suggests that repeated measurements do not necessarily provide valid measures of individual intake $(39,40)$. However, the patterns of bias from individuals in Japan may be different from those in Western countries; therefore further research of Japanese subjects is required.

Although the word misreporting (under- and overreporting) has been widely used to describe the phenomenon of mismeasurement (under- and overestimation) of food intake $(7,28)$, the word mismeasurement (underand overestimation) was used in the present paper. Error in dietary assessment can occur during all stages of the collection and recording of food consumption data (41). The phenomenon may therefore be more accurately described as mismeasurement because a wide range of factors such as undereating (dieting), incorrect estimation of portion size, and coding and computation errors are involved but not limited to the 
reporting ability of the subjects (42).

In conclusion, the use of the Goldberg cut-off demonstrated that almost half of EI examined here had only a $2.5 \%$ likelihood of reflecting habitual EI for a sedentary lifestyle given that the Goldberg equation calculates the lower and upper 95\% confidence limits of EI/BMR assuming a given PAL requirement. All dietary assessment methods are ultimately dependent on the motivation, compliance, and ability of subjects to accurately report their habitual food intake (43), and the common assumption that carefully collected dietary data are valid may not be necessarily true (2). It should not be considered, however, that dietary assessment is not worth doing, because the study of diet and health must include the measurement of diet (2). Instead of considering that responsible investigators should acknowledge the possibility of the bias, examine reported dietary intake data very critically and be cautious in drawing conclusions (39). The effort to improve dietary assessment methods should also be continued.

\section{REFERENCES}

1) Barrett-Connor E. 1991. Nutrition epidemiology: how do we know what they ate? Am J Clin Nutr 54: 182S$187 \mathrm{~S}$.

2) Black AE, Goldberg GR, Jebb SA, Livingstone MBE, Cole TJ, Prentice AM. 1991. Critical evaluation of energy intake data using fundamental principles of energy physiology: 2. Evaluating the results of published surveys. Eur J Clin Nutr 45: 583-599.

3) Livingstone MBE. 1995. Assessment of food intakes: are we measuring what people eat? Br J Biomed Sci 52: 5867.

4) Buzzard M. 1998. 24-hour dietary recall and food record methods. In: Nutritional Epidemiology, 2nd ed (Willett W, ed), p 50-73. Oxford University Press, New York.

5) Livingstone MBE, Black AE. 2003. Markers of the validity of reported energy intake. J Nutr 133: 895S-920S.

6) Gibson RS. 1990. Validity in dietary assessment methods. In: Principles of Nutritional Assessment (Gibson RS, ed), p 117-136. Oxford University Press, New York.

7) Tomoyasu NJ, Toth MJ, Poehlman ET. 2000. Misreporting of total energy intake in older African Americans. Int J Obes 24: 20-26.

8) Taren DL, Tobar M, Hill A, Howell W, Shisslak C, Bell I, Ritenbaugh C. 1999. The association of energy intake bias with psychological scores of women. Eur J Clin Nutr 53: 570-578.

9) Subar AF, Kipnis V, Troiano RP, Midthune D, Schoeller DA, Bingham S, Sharbaugh CO, Trabulsi J, Runswick S, Ballard-Barbash R, Sunshine J, Schatzkin A. 2003. Using intake biomarkers to evaluate the extent of dietary misreporting in a large sample of adults: The OPEN Study. Am J Epidemiol 158: 1-13.

10) Sasaki S, Yanagibori R, Amano K. 1998. Validity of a self-administered diet history questionnaire for assessment of sodium and potassium-Comparison with single 24-hour urinary excretion-. Jpn Circ J 62: 431435 .

11) Ebine N, Feng JY, Homma M, Saitoh S, Jones PJH. 2000. Total energy expenditure of elite synchronized swimmers measured by the doubly labeled water method. Eur
J Appl Physiol 83: 1-6.

12) Sasaki $S$, Ushio F, Amano K, Morihara M, Todoriki T, Uehara Y, Toyooka T. 2000. Serum biomarker-based validation of a self-administered diet history questionnaire for Japanese subjects. J Nutr Sci Vitaminol 46: 285-296.

13) Ebine $\mathrm{N}$, Rafamantanantsoa $\mathrm{HH}$, Nayuki $\mathrm{Y}$, Yamanaka K, Tashima K, Ono T, Saitoh S, Jones PJH. 2002. Measurement of total energy expenditure by the doubly labelled water method in professional soccer players. $J$ Sports Sci 20: 391-397.

14) Ebine N, Shimada M, Tanaka H, Nishimuta M, Yoshitake Y, Saitoh S, Jones PJH. 2002. Comparative study of total energy expenditure in Japanese men using doubly labeled water method against activity record, heart rate monitoring, and accelerometer methods. Tairyoku Kagaku (Jpn J Phys Fitness Sports Med) 51: 151-164 (in Japanese).

15) Iso H, Moriyama Y, Yoshino K, Sasaki S, Ishihara J, Tsugane S. 2003. Validity of the self-administered food frequency questionnaire used in the 5-year follow-up survey for the JPHC Study to assess folate, vitamin B6 and B12 intake: comparison with dietary records and blood level. J Epidemiol 13: S98-S101.

16) Karita K, Sasaki S, Ishihara J, Tsugane S. 2003. Validity of a self-administered food frequency questionnaire used in the 5-year follow-up survey of the JPHC Study to assess selenium intake: comparison with dietary records and blood levels. J Epidemiol 13: S92-S97.

17) Kobayashi M, Sasaki S, Kawabata T, Hasegawa K, Tsugane S. 2003. Validity of a self-administered food frequency questionnaire used in the 5-year follow-up survey of the JPHC Study Cohort I to assess fatty acid intake: Comparison with dietary records and serum phospholipid level. J Epidemiol 13: S64-S81.

18) Kobayashi M, Sasaki S, Tsugane S. 2003. Validity of a self-administered food frequency questionnaire used in the 5-year follow-up survey of the JPHC Study Cohort I to assess carotenoids and vitamin $\mathrm{C}$ intake: comparison with dietary records and blood level. J Epidemiol 13: S82-S91.

19) Sasaki S, Ishihara J, Tsugane S. 2003. Validity of a selfadministered food frequency questionnaire in the 5year follow-up survey of the JPHC Study Cohort I to assess sodium and potassium intake: comparison with dietary records and 24-hour urinary excretion level. J Epidemiol 13: S102-S105.

20) Touno M, Rafamantanantsoa HH, Ebine N, Peng H-Y, Yoshitake Y, Tanaka H, Saitoh S. 2003. Measurement of total energy expenditure in Japanese firefighters under normal working condition using the doubly labeled water method. Tairyoku Kagaku (Jpn J Phys Fitness Sports Med) 52: 265-274 (in Japanese).

21) Tsugane S, Sasaki S, Kobayashi M, Tsubono Y, Akabane M. 2003. Validity and reproducibility of the self-administered food frequency questionnaire in the JPHC Study Cohort I: study design, conduct and participant profiles. J Epidemiol 13: S2-S12.

22) Egami I, Wakai K, Kaitoh K, Kawamura T, Tamakoshi A, Lin Y, Nakayama T, Sugimoto K, Ohno Y. 1999. Intraand inter-individual variations in diets of the middleaged and the elderly. Nippon Koshu Eisei Zasshi (Jpn J Public Health) 46: 828-837 (in Japanese).

23) Tokudome S, Imaeda N, Tokudome Y, Fujiwara N, Nagaya T, Sato J, Kuriki K, Ikeda M, Maki S. 2001. Rela- 
tive validity of a semi-quantitative food frequency questionnaire versus 28 day weighed diet records in Japanese female dietitians. Eur J Clin Nutr 55: 735742.

24) Tokudome Y, Imaeda N, Nagaya T, Ikeda M, Fujiwara N, Sato J, Kuriki K, Kikuchi S, Maki S, Tokudome S. 2002. Daily, weekly, seasonal, within- and between-individual variation in nutrient intake according to four season consecutive 7 day weighed diet records in Japanese female dietitians. J Epidemiol 12: 85-92.

25) Ishihara J, Sobue T, Yamamoto S, Yoshimi I, Sasaki S, Kobayashi M, Takahashi T, Iitoi Y, Akabane M, Tsugane S. 2003. Validity and reproducibility of a self-administered food frequency questionnaire in the JPHC Study Cohort II: Study design, participant profile and results in comparison with Cohort I. J Epidemiol 13: S134S147.

26) Tsugane S, Kobayashi M, Sasaki S. 2003. Validity of the self-administered food frequency questionnaire used in the 5-year follow-up survey of the JPHC Study Cohort I: Comparison with dietary records for main nutrients. J Epidemiol 13: S51-S56.

27) Goldberg GR, Black AE, Jebb SA, Cole TJ, Murgatroyd PR, Coward WA, Prentice AM. 1991. Critical evaluation of energy intake data using fundamental principles of energy physiology: 1. Derivation of cut-off limits to identify under-recording. Eur J Clin Nutr 45: 569-581.

28) Black AE. 2000. Critical evaluation of energy intake using the Goldberg cut-off for energy intake:basal metabolic rate. A practical guide to its calculation, use and limitations. Int J Obes 24: 1119-1130.

29) Schofield WN. 1985. Predicting basal metabolic rate, new standards and review of previous work. Hum Nutr Clin Nutr 39C: $5-41$.

30) Kenko Eiyo Joho Kenkyu-kai. 1999. Recommended Dietary Allowances. Dietary Reference Intakes. Daiichi Shuppan Publishers, Tokyo (in Japanese).

31) Yamamura C, Kashiwazaki H. 2002. Factors affecting the post-absorptive resting metabolic rate of Japanese subjects: Reanalysis based on published data. Eiyogaku Zasshi (Jpn J Nutr Diet) 60: 75-83 (in Japanese).

32) Rafamantanantsoa HH, Ebine N, Yoshioka M, Yoshitake Y, Tanaka H, Saitoh S, Jones PJH. 2003. The role of exercise physical activity in varying the total energy expenditure in healthy Japanese men 30 to 69 years of age. J Nutr Sci Vitaminol 49: 120-124.

33) $\mathrm{FAO} / \mathrm{WHO} / \mathrm{UNU}$. 1985. Energy and protein requirements. Report of a Joint FAO/WHO/UNU Expert Consultation. Technical Report Series 724. World Health
Organization, Geneva.

34) Willett W, Stampfer MJ. 1986. Total energy intake: implications for epidemiologic analyses. Am J Epidemiol 124: $17-27$.

35) Owaki A, Takatsuka N, Kawakami N, Shimizu H. 1996. Seasonal variations of nutrient intake assessed by 24 hour recall method. Eiyogaku Zasshi (Jpn J Nutr) 54: 1118 (in Japanese).

36) Ogawa K, Tsubono Y, Nishino Y, Watanabe Y, Ohkubo T, Watanabe T, Nakatsuka H, Takahashi N, Kawamura M, Tsuji I, Hisamichi S. 1999. Inter- and intra-individual variation of food and nutrient consumption in a rural Japanese population. Eur J Clin Nutr 52: 781-785.

37) Black AE, Coward WA, Cole TJ, Prentice AM. 1996. Human energy expenditure in affluent societies: an analysis of 574 doubly-labelled water measurements. Eur J Clin Nutr 50: 72-92.

38) Livingstone MBE, Prentice AM, Strain JJ, Coward WA, Black AE, Barker ME, McKenna PG, Whitehead RG. 1990. Accuracy of weighed dietary records in studies of diet and health. BMJ 300: 708-712.

39) Black AE, Cole TJ. 2001. Biased over- or under-reporting is characteristic of individuals whether over time or by different assessment methods. J Am Diet Assoc 101: 70-80.

40) Kroke A, Klipstein-Grobusch K, Voss S, Moseneder J, Thielecke F, Noack R, Boeing H. 1999. Validation of a self-administered food-frequency questionnaire administered in the European Prospective Investigation into Cancer and Nutrition (EPIC) Study: comparison of energy, protein, and macronutrient intakes estimated with the doubly labeled water, urinary nitrogen, and repeated 24-h dietary recall methods. Am J Clin Nutr 70: $439-447$.

41) Gibson RS. 1990. Measurement errors in dietary assessment. In: Principles of Nutritional Assessment (Gibson RS, ed), p 85-96. Oxford University Press, New York.

42) Barnard JA, Tapsell LC, Davies PSW, Brenninger VL, Storlien LH. 2002. Relationship of high energy expenditure and variation in dietary intake with reporting accuracy on 7 day food records and diet histories in a group of healthy adult volunteers. Eur J Clin Nutr 56: 358-367.

43) Livingstone MBE, Prentice AM, Coward WA, Strain JJ, Black AE, Davies PSW, Stewart CM, McKenna PG, Whitehead RG. 1992. Validation of estimates of energy intake by weighed dietary record and diet history in children and adolescents. Am J Clin Nutr 56: 29-35. 